\title{
Principles of Smart Home Control
}

\author{
Scott Davidoff, Min Kyung Lee, Charles Yiu, John Zimmerman + Anind K. Dey \\ Human-Computer Interaction Institute + School of Design \\ Carnegie Mellon University \\ \{ scott.davidoff | mklee | cmyiu | johnz | anind \} a cmu.edu \\ http://smarthome.cs.cmu.edu
}

\begin{abstract}
Seeking to be sensitive to users, smart home researchers have focused on the concept of control. They attempt to allow users to gain control over their lives by framing the problem as one of end-user programming. But families are not users as we typically conceive them, and a large body of ethnographic research shows how their activities and routines do not map well to programming tasks. End-user programming ultimately provides control of devices. But families want more control of their lives. In this paper, we explore this disconnect. Using grounded contextual fieldwork with dual-income families, we describe the control that families want, and suggest seven design principles that will help end-user programming systems deliver that control.
\end{abstract}

\section{Introduction}

In order for smart homes to achieve their promise of significantly improving the lives of families through socially appropriate and timely assistance, they will need to sense, anticipate and respond to activities in the home. Interestingly, expanding system capabilities can easily overstep some invisible boundary, making families feel at the mercy of, instead of in control of that technology [1][5][6][21][30]. An important goal of smart home research then becomes how to appropriately expand system capabilities to produce more control - both perceived and actual.

Researchers often frame the problem of control as one of end-user programming [13][21][27][34]. However, end-user programming as it is typically conceived requires a priori specificity and rigidity that conflict with a large body of ethnographic research on the organic, opportunistic, and improvisational ways that families construct, maintain, and modify their routines and plans, e.g. [3][14][15][16][17][25] [26][38][42][45].

In exploring the issue of control and the smart home, we have chosen to focus on dual-income families, a large and growing segment of the population of the United States. These families often feel out of control due to the complex and rapidly changing logistics that result from integrating and prioritizing work [41], school, family [10], and enrichment activities [3][15][17][25].

While end-user programming returns some measure of control to the user over preprogrammed or learning-only systems [1][21], ultimately, framing the problem as end-user programming leads researchers to view the research and evaluation in terms 
of control of devices. Our fieldwork on dual-income families, however, shows that more than control of their devices, families desire more control of their lives. We suggest that the problem of home control should be widened to include not just control of artifacts and tasks, but control of the things families most value - their time, their activities, and their relationships. We argue that the way to do this is to enable end-user programming systems to more flexibly and appropriately reflect the complex nature of observed human interaction.

In this paper, we discuss how a smart home might provide dual-income families with more control over their lives. We describe the approach current end-user programming systems take to the problem of control. We then describe an ethnography we conducted with this population, and then situate our findings within the existing body of social research to outline a rich description of the kind of control families value, and the flexibility they utilize to manage their daily lives. Finally, based on these findings, we define seven principles to help researchers operationalize this concept of families being in control of their lives, as applied to end-user programming systems.

\section{Related Work}

As research in ubiquitous [48] and context-aware [18] computing moves into the home, and systems begin to take action on behalf of users [22] either in a proactive or reactive sense, researchers are finding that users feel unexpectedly challenged by these systems [30].

In traditional desktop models of human-computer interaction, systems are slaves to human input. But advanced context-aware systems can break this interaction model [6], and, in doing so, they challenge or even invert the user's sense of who is actually in control. Expanding system capabilities while maintaining users' sense of control then becomes one of the central concerns of context-aware computing.

One approach views the problem of smart home control in terms of end-user programming (in this paper we use the terms end-user programming and smart home control interchangeably). These end-user programming systems explore various interfaces to provide end-users control of home devices, including natural language [27], interlocking puzzle pieces [34], visual programming [35], programming by demonstration [19], and magnetic refrigerator poetry [46]. The end-user programming approach has several benefits. It provides users control over an unpredictable confederation of interoperating devices [40], and allows users to customize services as they might see fit [34], even inventing new services [46].

Existing end-user programming systems, however, also face certain limitations, especially in relation to how they might apply to dual-income families. First, families resist categorization as users. The user tends to be singular, while families are, by definition, plural. Unlike users, families both individually and collectively resist clearly-defined goals [15][17][38]. Also, family relationships are complex and evolve organically over time [10][16], whereas conceptions of the user tend to be static.

In addition, programming requires definition, formality, and specification which conflict with a large body of ethnographic research on how families operate. Respon- 
sibility or ownership of tasks in a family is rarely clearly-defined [3][16], while the majority of programming tasks connote clear lines of ownership. Also, various individuals have multiple [26] (often competing [25]) methods of completing tasks and metrics for the quality of their performance [16], while programming requires clear boundaries for task completion. Lastly, most programming tasks assume complete access to relevant information, and the focused attention of the programmer. But rapid context switching between home and work oblige families to make decisions with incomplete information [2] and marginal attention [41].

But most importantly, end-user programming studies define success in terms of usability, and overlook other core metrics contained in the human value proposition [43]. Systems are designed to facilitate the successful completion of tasks that often involve configuration of and complex interaction with multiple devices. But we suggest that usability measures should be contained within the larger discussion of value, which include utility and likeability [43].

We are suggesting that end-user programming consider not just the usability of the system, and how the users manage the artifacts that constitute it, but what utility the system is ultimately responsible for delivering. Existing end-user programming systems that focus on artifacts cannot repair the diminished sense of control that dualincome families already experience. But by expanding their evaluation metric to include the utility smart home systems provide, end-user programming systems might be able to help families regain a sense of control over their lives.

To understand how to appropriately support families in making that transition, we undertook an ethnography of dual income families. Here, our work builds upon the comprehensive studies of Darrah [14][15][16] and Beech et al [3]. While our work focuses on issues of routines, planning and control, other studies of family life have focused on household communication [13] and its relationship to locations [24], time management [25], communication technology [26], use of refrigerator magnets [44], knowledge specialization [42], routines [45], overall technology use [47], or calendaring [7].

\section{Ethnography of Dual-Income Families}

\subsection{Participants}

Our study began with an exploration of the needs of 12 dual-income families with school age children. These families represent an interesting population for several reasons. First, at $43 \%$ of the population of the United States and growing [32], dualincome families represent a significant demographic whose sheer magnitude merits attention.

In addition, dual-income families show a particular need for support. By moving away from the single-income model, these families are exposed to a surprising variety of stressors [14][15][32]. Taxing schedules and no anchor presence at home impose particularly high coordination costs. Parents are also exposed to role strain, where 
they feel pressures in trying to comply with the expectations attached to their roles as parents [2][12], which adds to an already stressful existence.

Lastly, we believe dual-income families are realistically poised to receive the benefits of smart home advances. The challenges dual-income families face often drive them to aggressively adopt and experimentally use new communication and coordination technologies [26]. Their demonstrated desire for increased flexibility and control over their own lives, and this historical precedent of using technology to satisfy those needs, we believe places dual-income families as prime candidates to become smart home early adopters.

Our families were solicited through bulletin board advertisement, and in person at shopping malls. We pre-screened families in order to include a wide range of professions, ages of parents and children, and economic class. Since our interest includes end-user programming, we also disqualified families where one of the parents had a job involving programming. Table 1 contains information about each of the families we recruited.

Table 1. Detailed description of participating families

\begin{tabular}{|c|c|c|c|}
\hline Family & Mother & Father & Children \\
\hline A & $\begin{array}{l}\text { Not provided, } \\
\text { Administrative assistant }\end{array}$ & Not provided, Carpenter & $\begin{array}{l}15 \text {, son } \\
18 \text {, son }\end{array}$ \\
\hline B & 47, Department manager & 48, Art gallery director & $\begin{array}{l}9 \text {, daughter } \\
15 \text {, daughter }\end{array}$ \\
\hline $\mathrm{C}$ & 41, Professor & 39, Teacher & $\begin{array}{l}1, \text { son } \\
5, \text { daughter }\end{array}$ \\
\hline D & 38, Business manager & 41, Marketing manager & $\begin{array}{l}5, \text { son } \\
8 \text {, daughter } \\
10, \text { son }\end{array}$ \\
\hline E & Not provided, Professor & Not provided, Carpenter & 15 , son \\
\hline $\mathrm{F}$ & 45, Secretary & 46, Truck driver & 15 , daughter \\
\hline $\mathrm{G}$ & 32 , Surgeon & 31, Graduate student & 5 , son \\
\hline $\mathrm{H}$ & 36, Project manager & 34 , Graduate student & $\begin{array}{l}\text { 1, daughter } \\
5 \text {, daughter }\end{array}$ \\
\hline I & 52, Nurse & 53 , Steam fitter & $\begin{array}{l}15 \text {, son } \\
19, \text { daughter }\end{array}$ \\
\hline $\mathbf{J}$ & 49, Administrative assistant & 50, Manager & $\begin{array}{l}15 \text {, daughter } \\
20 \text {, son }\end{array}$ \\
\hline $\mathrm{K}$ & 54 , Events coordinator & 55, Salesman & 21, son \\
\hline $\mathrm{L}$ & 43, Legal secretary & 46, Landscaper & $\begin{array}{l}\text { 11, daughter } \\
15 \text {, daughter } \\
17 \text {, daughter } \\
19 \text {, daughter }\end{array}$ \\
\hline
\end{tabular}

Participant homes averaged 2.3 bedrooms, and 6.6 rooms in total. Five homes had two floors, while the remaining seven had one floor. A typical footprint would include 
a modest family space near the front door connected to a small dining area. The kitchen area would form the hub of the home, while bedrooms were situated on the periphery or on the second floor.

\subsection{Method}

Fieldwork began with three-hour contextual interviews in the homes of the families. Time was organized to include directed storytelling, artifact walkthrough [8], and role-playing activities. The entire family was asked to participate in all the research activities.

Fieldwork pilots identified the "wake up" and "arrive home" times as key opportunity areas for smart home assistance, so we focused our investigation on those time windows. During directed storytelling we solicited personal accounts of waking up or arriving home from particular family members. In addition, we asked them to act out the scenes so we could better understand the relationship between their routine and its context. During the artifact walkthrough, we asked families to demonstrate the use of their main coordination artifacts, often a large kitchen calendar, and their various personal calendars. During role-playing, we asked families to pretend to coordinate for a fictitious school field trip, for which we provided simulated school paperwork. The interviews covered both predictable days, like weekdays and weekends, predictable exceptions like business trips and holidays, and unpredictable exceptions such as sick days or miss-the-bus days.

To gain additional insight into the wake-up and arrive-home activities, we left families with a cultural probe package [29]. The package explored the stressors and pleasures of waking up and arriving home. We also asked parents to comment on the parts of their lives that make them feel like good moms and dads. The package included a book of stimuli questions, free response text space, and a camera to photograph related vignettes.

Finally, we asked each family to log their wake-up and arrive-home activities for one week. We captured stress and rush levels, principal activities, immediate needs, and preoccupations.

\subsection{Data analysis}

To analyze our data, we mapped each home, photographed objects and locations of interest, and recorded photo locations on our maps. We coded our interview notes for emergent themes. We also evaluated our photographic record, grouping images to provide both visual support for themes identified during interviews, and themes that contained uniquely visual information, often place- or object-related.

We created individual schedules for each family member, including typical days (often weekdays), and regular exceptional days (like weekends), and occasional exceptional days (e.g. snow days, holidays). Schedules included both an order of activity and, if available, a corresponding time. Multiple timelines allowed us to compare order of operations both within and between families. 
The cultural probes helped us identify emotional connections between families and their homes, and how families define themselves through their products and their uses with them.

Finally, the activity $\operatorname{logs}$ allowed us to identify specific stress triggers and compare stress levels between weekdays and weekend days. They also provided rich description of family priorities when faced with competing needs.

\section{Findings}

Many of the logistical challenges that produce this feeling of "life out of control" can be traced to the enrichment activities that children participate in. While work and school add to the complexity of daily living, they tend to present predictable logistical needs. But many qualities of enrichment activities make them resistant to simple logistical management.

Enrichment activities present rapid seasonal changes. They also require constantly evolving transportation needs. And they often present both anticipated and unanticipated attendant responsibilities. These factors make them much more resistant to the development of a consistent routine and much more likely to cause a breakdown requiring improvisation to the underlying logistical plan.

Other sources of loss of control can be attributed to unpredictable events and breakdowns, like sick children, or missing the school bus.

Generally our families address this loss of control by increasing their flexibility. We consider this situation in more detail.

\subsection{Less than ideal control}

Enrichment activities frame the day. Dual-income families fill their children's lives with enrichment activities. These activities benefit the children in many ways such as teaching values, providing physical fitness, teaching competition and teamwork, supporting existing social structure and providing supplemental education. Families often select activities based on long-term goals such as preparing their kids for a successful career or increasing the chance of college admission to selective schools [15]. In addition, the activities often serve as de facto "babysitting" to help cover the time parents are at work. Every child in every family we interviewed participated in at least one (and on average two) enrichment activities.

While children form the principal participants, enrichment activities affect every member of the household. In addition to the management of their households and the completion of whatever work they might have brought home, parents are charged with the successful logistical management of their children as they relate to these activities. 
Even the simple is complex. Family J's soccer practice shows how much logistical complexity can be contained within a single event. First, getting the kids wherever they need to be represents a challenge. Practices are held in one of two locations. Games are held in any number of locations. Locations are printed on the team schedule, which is kept on the family refrigerator. This sheet has no directions. Parents who carpool have to coordinate who picks up and who drops off. Practices start at consistent times, but games start at one of three times.

Kids also have to come prepared. If the event is on turf, kids will need to bring their flat shoes. If the event is on grass, they will need to bring their cleats. Kids always need to bring their shin guards and knee pads. Games require either the home or away uniform. Practices require practice jerseys. All clothes need to be laundered, which often means washing them the night before so that they are clean for the day of use.

Even parents have homework for soccer games. Three families bring refreshments to each game - juice for thirsty players during the game, juice for after the game, and oranges for halftime. This information is also encoded on the schedule on the fridge. Forgetting comes with a high social cost. Either the team goes thirsty, and the child is embarrassed, or the parent has to face the panic and stress of racing to get kids to the field on time while running to the store to buy drinks and fruit.

A simple activity, like leaving the house, is rarely "simple." To get the kids to school, parents need to make sure children are awake, washed, dressed, fed, and ready for their rides. These activities depend on the (sometimes unwilling) participation of the child(ren), the coordinated use of (or competition for) scarce resources (e.g., bathroom time) with other family members, and the presence of these and other resources (e.g., school bag) along with the knowledge of their whereabouts. Our Family H's Dad described a successful morning as one where "we all get out the door, and there are no major disasters."

Activities resist routinization. Routines allow families to function without having to carefully consider every option at every moment [45]. However, routines for enrichment activities prove difficult to construct. And even when possible, these routines provide many opportunities to break down. Their high variability in both detail and responsibility make construction of a "normal" routine difficult. In addition, most of these activities do not run for an entire year. Instead they are "seasonal," forcing families to constantly re-adjust schedules as seasons end and new seasons begin.

Transportation to activities such as team sports almost always involves variability in the routine. Most dual-income parents needed to rely on others to provide some transportation due to other commitments in their complex schedules and due to the different locations and times of the events. In addition, most activities required inconsistent use of special equipment such as the types of shoes and uniforms mentioned above. 
Responsibilities bleed past fixed boundaries. Timing and order also play major roles in the capable execution of enrichment activities, adding further to their logistical complexity. Many activities, like musical groups, require special equipment. And since children often go to their activities directly from school, children must take this equipment with them in the morning, extending the time window of responsibility to the morning of the event. For Family H, washing soccer uniforms extended responsibility to the night before the event.

Responsibility can even extend significantly further than a single day. Family $\mathrm{H}$, for example, has to bring in snacks for the entire class one day each month. Parents have to remember this day, and make sure to have enough snacks for the entire class in the house on the morning of the day on which the snack is their responsibility. This extends the time window for the event as far back as the weekend before the event, when Family H would go food shopping for the week.

Breakdowns cause cascade effects. Because children and parents are so interdependent, their schedules are united by a chain of dependency. Small failures that affect one individual can extend individual failures into multiple, shared coordination failures. We found this scenario to be common among our participant families: Mom might be running behind for a business meeting, so she needs the bathroom first. Her Son is forced to shower second, and misses his bus. Dad then has to drive him to school, which makes him late for his morning meeting.

The chain of dependency can also become more complex when parents, out of necessity, divide the jobs surrounding certain tasks. For example, in Family H, it is Dad's job to get their Daughter ready for ballet, and it is Mom's job to take their Daughter to ballet as part of a carpool. When Mom goes away on a business trip, and the carpool parent providing the ride calls with a cancellation, Dad lacks the resources to easily arrange a new ride. He does not know which other parents he can lean on, as this task is not part of his regular responsibilities.

Not enough gas in the car, traffic, a forgotten briefcase, an extra trip to the grocery store - all simple events that might delay one person - cascade into the schedules of other family members, who all depend on one another.

"Busyness" is a moral good. It would seem that if enrichment activities caused so much distress and made families feel "out of control", then a simple strategy to regain control would be to do less. However, this strategy is conspicuously absent in dualincome families. The parents in our ethnography value the enrichment their children receive through participation in these activities. In addition, participation allows them to demonstrate their mastery of "busyness", and the ability to master busyness is one of the values these families who have generally self-selected to be dual-income wish to pass on to their children [14][16].

\subsection{Flexibility as coping strategy}

Families exhibited many behaviors that allow them to manage this hyper-busyness. Some families imposed simple rules. Family L, for example, limited their four chil- 
dren to no more than three activities each. Many families assigned responsibilities for specific events to particular parents, liberating the other parent from dealing with those details. All our families leveraged some technological infrastructure [26] and had routines surrounding its use.

In general, we observed across almost all coping strategies, a quality of flexibility. We explain in more detail by example.

Detail is acquired when necessary. One flexibility strategy involved incrementally adding details to plans as they became necessary. This tendency causes long-term plans to differ substantially from short-term plans.

Long-term plans tend to resemble rough sketches. When Family $\mathrm{H}$ learns their day for snacks is weeks away, Mom puts the snack calendar on the fridge. She does not consider what snack to get at that time because what she buys will depend in part on what her daughter wants and what other families have provided that week. She doesn't know if she will purchase the snack when food shopping the weekend before or if Dad will have time to pick it up on his way home the night before. Only summary knowledge is either known or even possible to be known.

But on the day of certain activities every logistical detail has to be covered. The night before a soccer game, just before dinner, for example, Family $\mathrm{H}$ consults the various media that include information relevant to that game: the location, home or away, who is dropping off, and who is picking up. Mom knows it is her job to pick up, so she confirms with her Daughter where to wait for her. Mom also confirms who else she will be taking in the carpool. Mom confirms all the details and places just to be sure that nothing had changed since its codification on the central artifacts.

Improvise. Many events never acquire any a priori detail at all. Sometimes, this was due to constraints of memory. Family H, for example, reported keeping "only two or three [plans] in our head at one time." And so on days when there were multiple events after school, Mom and Dad would speak on their cell phone multiple times and watch many plans evolve without preplanned conception of their ultimate order of operations. In fact, we observed that many plans started out as successful improvisations, and then were adopted as routines because of that success.

Frissen [26] and Darrah [16] also describe parents adopting new communication technology so that they could become more available and ultimately increase their flexibility. Because they could be reached by their families at a moment's notice, plans were able to evolve and be improvised even closer to their target times.

Work and home blend. Mom and Dad also tend to bring their work life home, and arrange their home life at work [41]. By bringing the two contexts together, parents don't have to constrain all their home planning to the house, or all their work planning to the office. This ability to seamlessly move between contexts allows for plans to dynamically evolve, and allows for more flexibility in how time is used. In Family F the Mother worked at home in the evenings close to her daughter to allow her to focus both on work and her family simultaneously.

This flexible changing between home and work also extends to artifacts. Parents would seamlessly shift between whatever media was most immediately available [3] 
[13][26]. We found that our families stored work information on their home calendar, and home information on their work calendar [25]. This opportunistic use of media helps parents master their busyness while, at the same time, complicates their lives by requiring synchronization between the many artifacts that impact the different aspects of their lives.

Lifestyle choices. We observed families making deliberate choices about highly important parts of their lives so that they could have more flexible routines.

Family J chose to live close to Dad's work so that Dad could be available in emergencies. In [15], Darrah found families who would consolidate their children into one school so as to simplify logistics. Family L staggered their work schedules so that one parent could be more available for unexpected events, like children being sick.

\section{Design Principles}

The homes that we observed were inhabited by complex families full of contradictory human beings in need of support. To help these families regain control of their lives, researchers might try to help them make better lifestyle choices, including simply reducing the number of activities in which they are actively involved. But our findings suggest that these activities play a central role in the social identity of families and modifying them would damage this fundamental aspect of family life. Instead of proposing a social engineering solution, we approach the problem by exploring the role of technology in supporting families' existing lifestyles and identities.

Currently, we observe a disconnect between the nuanced lifestyles our study demonstrates, and the smart homes that many technologists envision. This suggests that for technology to help families regain control over their lives, we refocus the end-user programming of smart home systems to more appropriately reflect that complexity.

To begin this investigation into a new kind of end-user programming, we provide a list of principles that such a system would need to adhere to. The principles include the following:

1. Allow for the organic evolution of routines and plans

2. Easily construct new behaviors and modify existing behaviors

3. Understand periodic changes, exceptions and improvisation

4. Design for breakdowns

5. Account for multiple, overlapping and occasionally conflicting goals

6. The home is more than a location

7. Participate in the construction of family identity

We address each principle in turn.

\subsection{Allow for the organic evolution of routines and plans}

Routines form the basis of normalcy in many domestic situations, and allow family members to focus their attention on other, more demanding activities [3][15][25][45]. 
Plans allow families to coordinate the substantial number of activities they carry out during an average day. Plans and routines represent an important and powerful way families manage to resist entropy and regain elements of control over their lives. Thus a smart home system that intends to provide families some measure of control over their lives must account for the concept of the routine. But routines, as we and others [45] have observed, contain many subtle inflections that resist the simple models of computation imposed by many end-user programming systems.

First of all, describing all the routines of a family would constitute an enormous undertaking. Next, our families would likely not recall all their routine behaviors, as some have simply become so routine that they have passed below consciousness [15]. But even known routines rarely conform to the notion that they might be able to be completely specified a priori. Many routines themselves were once successful improvisations that have been incorporated into a family's daily activities. Other plans begin with only cursory detail, and gain in precision as the day of their enacting encroaches.

On the surface, existing smart home control systems attempt to provide support for routines. But, their concept of routines is too rigid, requiring a priori specification of all the routines that the user can remember.

To give families a sense of control over their lives, a smart home system will have to both support the concept of routine, but not bind families to that notion. Such a system will need to allow plans and routines to evolve organically. Systems that enforce rigidity in routines, including most end-user programming systems built for the home, do not match our observations of how people behave and will not be successful at helping families take control of their lives. This inflexibility will lead to families losing control to the technology itself, replacing control with an inflexible algorithmic tyranny.

While an extreme case, evidence from the MavHome, a smart home research environment [11] illustrates this point well. The MavHome had a lighting model that turned off its lights late at night because its occupant did not have visitors late at night and was asleep. When the occupant did have visitors, they literally had to "remain in the dark" because of the difficulty in controlling and changing the home's behavior. Systems that support this design principle would have to incorporate the flexible, organic nature of routines that people adhere to themselves.

\subsection{Easily construct new plans and routines, and modify existing ones}

Many of our families engaged in planning and coordination tasks daily. We fully expect that families would interact just as frequently with a smart home system that supported the concepts of plans and routines. Such a smart home system would need to offer a low-cost way for families to describe plans and routines.

Additionally, given the need to support the organic evolution of routines, including occasional improvisation, and breakdowns and exceptions in those routines, this system will also need to provide a low-cost way to modify existing behaviors. 


\subsection{Understand periodic changes, exceptions and improvisation}

Even if routines could be specified entirely beforehand, people both intentionally and necessarily deviate from routines. Some deviation is seasonally mandated, such as children participating in soccer in the fall, and in basketball in the winter. Some deviation occurs due to exceptions - Mom wants to get a surprise gift for her daughter. Many routines are substantially improvisational, representing constantly shifting targets.

A smart home system that enforced a single, rigid correct model of routines would find that few routines were ever capably executed according to that model, and would be constantly interrupting and misinterpreting what was actually happening.

Once again, smart home technology that reflected observed behavior would have to understand that exceptions to routines are actually not exceptional, and be prepared to interpret them correctly. This means that a representation of a routine or plan cannot be rigid, and the system has to understand concepts like periodicity, what an exception is and how to recover from or adapt to it, and how to deal with improvisation. Simply put, any computational model that is expected to take action on behalf of families would be confronted with the fact that routines can prove to be anything but.

\subsection{Design for breakdowns}

Even when routines are capably carried out by family members, and the family machine marches forward like clockwork, we found many instances where the surrounding world simply did not cooperate. Family I's Dad gets the kids ready for school on time, but his Son's shoes have gone mysteriously missing. The carpool stops while Dad scours the house for the delinquent footwear. Family J's Dad has to bring his Daughter to physical therapy after school. But she forgets, and goes to her friends' house. Mom has to drive out of her way to pick her Daughter up. Plans just don't always work. Routines sometimes fail. A smart home system will need to expect, account for, understand, and appropriately respond to these eventualities.

Also, a smart home would need to recognize when a breakdown is occurring and understand the kind of cascading failures that can occur and learn or know how to react to them and ideally avoid as many of the attendant failures as possible.

\subsection{Account for multiple, overlapping and occasionally conflicting goals}

Sometimes it is not the world, but the family structure itself that causes complexity or breakdowns in plans or routines. Laundry may be Mom's job on Monday, but it is Dad's job on Tuesday. These collaborative tasks suggest another aspect of the flexibility that a smart home system would have to reflect.

Many tasks simply do not fit a simple model of ownership. Family F's Daughter's is responsible for walking the dog every morning, except when she's running behind. In these circumstances, Mom was happy to help out. Other tasks resist the concept of ownership all together. Everybody in Family L shares in the laundry duties. Other 
tasks move between individuals on particular days of the week, muddling the notion that responsibility is owned by any single individual.

We also might find open conflict regarding a chore or routine [38]. Preferences vary widely for what constitutes a comfortable temperature, and many families battle over the thermostat. Other conflicts may surround varying methods for task completion, varying tolerances and metrics of quality, or the priority of a particular task. For example, Mom may make a rule that says "don't use the scrubber on the pots." But everybody in the family knows the rule really means "don't use the scrubber on the pots when Mom's in the room."

A smart home system would need to participate in this ambiguous notion of responsibility. A smart home may need to face, interpret and react to a situation where goals conflict and the situation may still be valid. In such a situation, the system would have to provide a way to maintain internal consistency in data structure in the face of external disagreement.

\subsection{The house is more than a location}

As opportunistic planners, our families did not limit their coordination activities to the physical constraints of any single location within the house, or even the house itself. Planning and coordination also occur at work, at school, at the place of the activities themselves, and during transportation between any of these locations.

The functional boundaries of the smart home will need to extend beyond the physical parameters of the home itself, and be accessible anywhere planning for or activities receiving support occurs. A smart home that participates in a family's planning dialog will have to allow for the family to enter and update information from these various locations as easily as if they were at home.

This specification extends to routines as well. A smart house would need to support planning activities, and also be able to monitor everything else going on outside the home to better understand how routines are changing and whether breakdowns, exceptions and/or organic changes are taking place.

The blending of spaces also extends to information space. Families enter information in calendars at both home and work. Paper school flyers and sports schedules find their way onto refrigerators. Calendars also cross the boundaries of individuals. A smart home system that allows its inhabitants to feel in control of their information will need to be able to blend elements across contexts, media and individuals and aggregate them into a unified model of what is happening.

A smart home that supports this principle would support planning tasks and maintenance of routines everywhere the family goes, monitor and react to family activity in and out of the house and be able to leverage all available artifacts that the family uses.

\subsection{Participate in the construction of family identity}

Potential smart home services might also potentially collide with how individual family members derive their identity. Consumption and use of products contribute to 
how people formulate their social identity [4][23][37]. And since the home represents the largest purchase most people ever make, to many families the home itself makes the largest product-based contribution through which they realize their social identity. By extension, we can expect that the services a smart home provides will in many ways contribute to how individuals formulate their social identity.

Here, grocery list support provides a good example. While cooking dinner every night might be challenging and a source of frustration for Mom, automating the cooking process could also remove an opportunity for Mom to feel like a good Mom [44]. The act of preparing food constitutes an important part of Mom's identity. Instead, automating the creation of a grocery list is an assistive task that aids Mom without challenging her identity.

Existing smart home systems often focus on the usability or efficiency of a particular task, but remove that task from the larger context in which it is so importantly embedded. Many tasks are time-intensive but are vital to our identities as Moms, Dads and Families. As researchers search for new services a smart home can provide, they will have to extend their evaluation metrics to include this important component of the human value proposition.

This understanding of how smart home services contribute to our identity also extends to situations where the smart home may take action on behalf of users. When a smart home system is making a decision about when it is appropriate to take an action, it has to be aware of these invisible value lines, and have some understanding of social protocol, so that it can decide when it is appropriate to cross those lines, and when it is not.

\section{Conclusions}

In this paper, we have presented seven principles that we believe smart home researchers should address in the systems they build, in order for families to take control of their lives. These principles were derived from an ethnography we conducted with dual-income families that illustrated the loss of control these families feel over their lives. Enrichment, work and school activities and the exceptions and breakdowns that can occur, combined with parents trying to instill their values into children all contribute to families' sense of loss of control.

Much of the smart home research that addresses control, leverages end-user programming. However, in practice, these systems promote control over artifacts and devices, rather than promoting control over the routines, planning and time (in short, the lives) of families. From our ethnography, we found that the key to regaining control over complex lives is to support flexibility.

Our design principles focus on providing flexibility in the planning of activities, construction and modification of routines, through support for organic formation of routines, along with support for exceptions, improvisation and breakdowns in those routines. They also suggest the need to accommodate conflicting goals and responsibilities among family members, to push the boundaries of the home beyond the physical construct of the home itself, and to participate in the construction of a positive family identity. 
We acknowledge that it will be difficult to embed these principles into working end-user systems, but our contribution is in pointing out that an end-user control system will likely fail unless it adheres to the principles. Our next step is to build and evaluate a smart home system that adheres to these principles and makes families be and feel more in control of their lives. An important goal in sharing these principles is to initiate a discussion with other smart home researchers about smart home occupants and their feelings of control. In particular, we hope to bring attention to the social and often chaotic nature of family life, the impact it has on smart home technology and the impact smart home technology can have on it.

\section{References}

[1] Barkhuus, L., \& Dey, A.K. (2003) Is context-aware computing taking control away from the user? Three levels of interactivity examined, Proceedings of Ubicomp 2003, 159-166.

[2] Barnett, R.C. (1994). Home-to-work spillover revisited: A study of full-time employed women in dual-earner couples, in Journal of Marriage and the Family, 56: 647-656.

[3] Beech, S., Geelhoed, E., Murphy, R., Parker, J., Sellen, A. \& Shaw, K. (2004) Lifestyles of working parents: Implications and opportunities for new technologies, HP Tech report HPL-2003-88 (R.1).

[4] Belk, R.W. (1988) Possessions and the extended self, Journal of Consumer Research, 15(2): 139-168.

[5] Bellotti, V., Back, M., Edwards, W.K., Grinter, R.E., Henderson, A., \& Lopes, C. (2002) Making sense of sensing systems: Five questions for designers and researchers, Proceedings of CHI 2002, 415-422.

[6] Bellotti, V. \& Edwards, W. K. (2001) Intelligibility and accountability: Human considerations in context-aware systems, Human-Computer Interaction, 16(2-4): 193-212.

[7] Bernheim Brush, A.J. \& Combs Turner, T. (2005) A Survey of personal and household scheduling, in Proceedings of Group 2005, 330-331.

[8] Beyer, H. \& Holtzblatt, K. (1998) Contextual design: Defining customer-centered systems, San Francisco: Morgan Kaufman Publishers.

[9] Blackwell, A.F., Burnett, M.F. \& Peyton Jones, S. (2004) Champagne prototyping: A Research technique for early evaluation of complex end-user programming systems, in Proceedgings of VLHCC 2004, 47-54.

[10] Cherlin, A. J. (1988) The Changing American family and public policy, Washington, D.C.: Urban Institute Press.

[11] Cook, D.J., Youngblood, M., Heierman, E., Gopalratnam, K., Rao, S., Litvin, A., \& Khawaja, F. (2003) MavHome: An agent-based smart home, in Proceedings of PerCom 2003, 521-524.

[12] Cowan, R. S. (1989) More Work for Mother, London: Free Association Books.

[13] Crabtree, A., Rodden, T., Hemmings, T. \& Benford, S. (2003): Finding a place for ubicomp in the home, in Proceedings of Ubicomp 2003, 208-226. 
[14] Darrah, C.N. \& English-Lueck, J.A. (2000) Living in the eye of the storm: controlling the maelstrom in Silicon Valley, in Proceedings of the 2000 Work and Family: Expanding the Horizons Conference.

[15] Darrah, C. N., English-Lueck, J. \& Freeman, J. (2001) Families at work: An ethnography of dual career families, Report for the Sloane Foundation (Grant Number 98-6-21).

[16] Darrah, C.N. (2003) Family models, model families, in Proceedings of the 2003 American Anthropological Association Annual Conference.

[17] Davidoff, S., Lee, M.K., Zimmerman, J. \& Dey, A.K. (2006) Socially-aware requirements for a smart home, in Proceedings of the International Symposium on Intelligent Environments, 41-44.

[18] Dey, A., Abowd, G., \& Salber, D. (2001) A conceptual framework and a toolkit for supporting the rapid prototyping of context-aware applications, Human-Computer Interaction, $16(2-4)$

[19] Dey, A.K., Hamid, R., Beckmann, C., Li, I., \& Hsu, D. (2004): a CAPpella: programming by demonstration of context-aware applications, in Proceedings of CHI 2004, 33-40.

[20] Dey, A.K., Sohn, T., Streng, S., \& Kodama, J. (2006) iCAP: Interactive Prototyping of Context-Aware Applications, in Proceedings of Pervasive 2006, 254-271.

[21] Dey, A.K., Newberger, A.N., \& Chau, E. (2006) Support for context monitoring and control, in submission.

[22] Dourish, P. (2004) What we talk about when we talk about context, Personal and Ubiquitous Computing, 8(1):19-30.

[23] Dittmar, H. (1989) Gender identity-related meanings of personal possessions, in British Journal of Social Psychology, 28(6):159-171.

[24] Elliot, K., Neustaedter, C., \& Greenberg, S. (2005) Time, Ownership and Awareness: The Value of Contextual Locations in the Home, in Proceedings of Ubicomp 2005.

[25] Fleuriot, C. (2001). An Investigation into the management of time in complex lifestyles, $\mathrm{Ph} . \mathrm{D}$ thesis, University of the West of England.

[26] Frissen, V.A.J. (2000) ICTs in the rush hour of life, The Information Society, 16: 65-75

[27] Gajos, K., Fox, H., \& Shrobe, H. (2002) End user empowerment in human centered pervasive computing, in Proceedings of Pervasive 2002, 1-7.

[28] Garfinkel, H. (1967) Studies in Ethnomethodology, Engelwood Cliffs, NJ: Prentice Hall.

[29] Gaver, B., Dunne, T., \& Pacenti, E. (1999) Design: Cultural probes, interactions, 6(1): 2129.

[30] Grinter, R.E. \& Edwards, W.K. (2001) At Home with ubiquitous computing: Seven challenges, In Proceedings of Ubicomp 2001, 256-272.

[31] Harper, R. (2003) Inside the smart home: Ideas, possibilities and methods. in Richard Harper (Ed.) Inside the smart home. New York: Springer, 1-14.

[32] Hayghe, H. V. (1989) Children in 2 worker families and real family income, in Bureau of Labor and Statistics' Monthly Labor Review, 112(12): 48-52.

[33] Hindus, D. (1999) The importance of homes in technology research, in Proceedings of CoBuild 1999, 199-207. 
[34] Humble, J., Crabtree, A., Hemmings, T., Åkesson, K., Koleva, B., Rodden, T., \&Hansson, P. (2003) "Playing with the bits": User-configuration of ubiquitous domestic environments, in Proceedings of Ubicomp 2003, 256-263.

[35] Jahnke, J.H., d'Entremont, M., \& Stier, J. (2002) Facilitating the programming of the smart home, IEEE Wireless Communications, 9(6): 70-76.

[36] Kidd, C., Orr, R.J., Abowd, G.D., Atkeson, C., Essa, I., MacIntyre, B., Mynatt, E., Starner, T., \& Newstetter, W. (1999) The Aware Home: A living laboratory for ubiquitous computing research, in Proceedings of CoBuild 1999, 191-198.

[37] Kleine, R.E., Kleine, S.S., \& Kernan, J.B. (1993) Mundane consumption and the self: A social identity perspective, in Journal of Consumer Research, 2(3): 209-235.

[38] McCalley, L. T., Midden, C. J. H. \& Haagdorens, K. (2005) Computing systems for household energy conservation: Consumer response and social ecological considerations, in Proceedings of CHI 2005 Workshop on Social Implications of Ubiquitous Computing.

[39] Mozer, M. (1998) The neural network house, in Proceedings of AAAI Symposium on Intelligent Environments, 110-114.

[40] Newman, M., Sedivy, J. Z., Neuwirth, C. M., Edwards, W. K., Hong, J. I., Izadi, S., Marcelo, K., \& Smith, T. F. (2002) Designing for serendipity: Supporting end-user configuration of ubiquitous computing environments, in Proceedings of DIS 2002, 147-156.

[41] Nippert-Eng, C. (1995) Home and work. Negotiating boundaries through everyday life. Chicago: University of Chicago Press.

[42] Rode, J.A., Toye, E.F. \& Blackwell, A.F. (2005) The domestic economy: A broader unit of analysis for end user programming, in Proceedings of CHI 2005, 1757-1760.

[43] Shackel, B. (1991). Usability - context, framework, definition, design and evaluation, in Shackel, B. \& Richardson, S. (Eds.) Human Factors for Informatics Usability, Cambridge, UK: Cambridge University Press, 21-37.

[44] Taylor, A.S. \& Swan, L. (2005) Artful systems in the home, in Proceedings of CHI 2005, 641-650.

[45] Tolmie, P., Pycock, J., Diggins, T., MacLean, A. \& Karsenty, A. (2002) Unremarkable computing, in Proceedings of CHI 2002, 399-406.

[46] Truong, K. N., Huang, E. M., \& Abowd, G. D. (2004) CAMP: A magnetic poetry interface for end-user programming of capture applications for the home, in Proceedings of Ubicomp 2004, 143-160.

[47] Venkatesh, A., Chuan-Fong E.S. \& Stolzoff, N.C. (2000) A Longitudinal analysis of computing in the home based on census data 1984-1997, in Proceedings of HOIT 2000, 205-215.

[48] Weiser, M. (1991) The computer for the 21st Century, Scientific American, 265(3): 94104. 